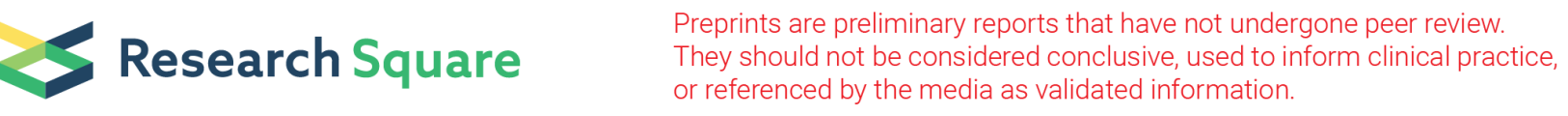

\title{
Are Temperament and Personality Redundant? A Longitudinal Comparison of Predictions With Childhood and Adulthood Personality
}

Amanda J. Wright ( $\nabla$ ajwright@wustl.edu )

Washington University in St. Louis

Joshua J. Jackson

Washington University in St. Louis

Research Article

Keywords: temperament, Big Five, personality prediction, Bayesian analysis, life outcomes

Posted Date: March 7th, 2022

DOI: https://doi.org/10.21203/rs.3.rs-1386963/v1

License: (c) (i) This work is licensed under a Creative Commons Attribution 4.0 International License. Read Full License 


\section{Abstract}

Debate has long surrounded whether temperament and personality are distinct sets of individual differences or are rather two sides of the same coin. To the extent that there are differences, it could indicate important developmental insights concerning the mechanisms responsible for linking traits with outcomes. One way to test this is to examine the joint and incremental predictive validity of temperament and personality in the same individuals across time. Using a longitudinal sample spanning three decades starting infancy and followed up to 37 years old $(N=7,081)$, we ran a series of Bayesian generalized linear models with measures of childhood temperament and adult-based personality to predict outcomes in several life domains. Results indicated that while each set of individual differences were often related to the same outcomes, there were instances in which temperament provided incremental validity above adult personality, ranging from $2 \%-10 \%$ additional variance explained. Temperament explained the most variance for outcomes such as cognitive ability and educational attainment whereas personality performed best for outcomes such as health status, substance use, and most internalizing outcomes. These findings indicate temperament and personality assessments are not redundant and that a lifespan approach is needed to understand fully understand life outcomes.

\section{Introduction}

Debate has historically surrounded whether childhood and adult personality are two sides of the same $\operatorname{coin}^{1-3}$, but despite the history of controversy, evidence indicates there is considerable overlap in childhood and adulthood personality traits ${ }^{4,5}$. If it were the case that adult personality is merely a later form of childhood temperament, one would reasonably expect an individual's earlier temperament and later personality to predict similar life outcomes and/or show redundant predictive validity. However, if there are predictive differences, this would point to a number of developmental insights concerning the mechanisms responsible for linking individual differences with life outcomes.

While childhood temperament does predict later adult outcomes ${ }^{6-8}$, it is unclear whether child and adult assessments are redundant in the prediction of life outcomes as no study has directly examined this question. Using a large-scale representative sample over thirty years, we directly test the incremental predictive validity of childhood temperament above later adult-based personality to assess the uniqueness between the two types of age-graded individual differences.

\section{Does It Matter When We Assess Personality?}

Given that personality is moderately consistent across the lifespan ${ }^{9-10}$, it is important to identify when personality is most important. Child and adult personality prediction of life outcomes can yield a number of patterns, each suggesting different mechanisms linking personality with life outcomes.

First, the "it doesn't matter when" pattern describes that if one wanted to predict outcomes with personality, any assessment across the lifespan would suffice. If childhood and adult personality traits equivalently predict future life outcomes, this would suggest the mechanisms linking traits measured at distinct points of individuals' lives operate similarly and, ultimately, yield equal predictions of future outcomes. In support of this perspective, both childhood and adulthood personality assessments predict similar outcomes $5,6,8,11$.

A second possible pattern of associations is "all that matters is where you end up." Whereas the previous pattern emphasizes the redundancy of assessments, this perspective suggests the strongest associations for assessments of personality are those closest in time to the outcomes they are trying to predict. As with any developmental processes, time introduces noise into the system. The result of this introduction of noise is that it continually builds and 
accumulates. This error generating process is (partly) the reason why decades-long longitudinal associations are weaker and harder to come by than associations closer in time ${ }^{12}$. This perspective puts emphasis on adulthood, and subsequently neglects childhood, as being relevant to understanding adult life outcomes such as health, wealth, and well-being.

The third pattern is the "it's where you start and finish." In contrast to the above pattern, this third perspective is that of a lifespan approach. It emphasizes that it is necessary to understand who an individual is throughout their entire life to best understand their current and future development. With this approach in mind, it becomes readily apparent that childhood personality is a rich source of individual differences that are inextricably related to an individual's status in life at any point in time.

Importantly, past studies provide a reasonable basis for expecting child and adult personality to uniquely predict outcomes. This notion is supported in part by the fact that although there is nonzero stability from childhood to adult personality, these associations tend to be modest ${ }^{10}$, thus allowing for within- and between-person change. Hill et al. (2019) outlined three overlapping processes that serve as potential mechanisms by which childhood personality differentially predict future adult outcomes compared to adult-based personality measures.

First, the opportunities and snares hypothesis suggest that there are child-relevant events and situations directly associated with adult outcomes ${ }^{13}$. Personality at this time is important because one cannot make up for lost time if these opportunities are passed. Childhood personality plays an important role in developmental branching such that it predisposes them to take certain paths in life. Taking certain paths early in life restricts the ease of or ability to take other paths later in life, which emphasizes the widespread, downstream consequences of this early-life branching. For example, children who score higher in effortful control tend to do better and work harder in school ${ }^{14,15}$. These children are then more likely to obtain higher levels of education ${ }^{16}$, which itself predicts other future positive outcomes. In comparison, children who score lower on related traits are more likely to engage in substance use ${ }^{17,18}$, which itself predicts even more frequent substance use and other delinquent behaviors in adulthood ${ }^{19}$.

Second, the differential maturation hypothesis posits that the trajectories and rates of personality development and change experienced prior to adulthood can affect future outcomes ${ }^{13}$. At the core of this idea lies individual differences in rates of change during childhood. If people change at different rates, then having multiple assessments of a construct is important. Third, the differential pathways hypothesis describes those pathways that explain why personality affects future success may differ across the lifespan ${ }^{13}$. For example, it might be expected that the effects of personality on income are mostly driven by adult personality trait levels (e.g., working productively versus counterproductive work behaviors ${ }^{20,21}$ ). However, the paths linking personality and financial success may begin much earlier in life such as through greater educational attainment.

\section{Current Study}

In a longitudinal study of more than 7,000 individuals assessed from birth to adulthood, we predicted outcomes in several life domains (e.g., health, relationships, career) using multi-method assessments of child and adult personality measured upwards of 30 years apart. We address two key questions, both from the lens of explaining variance in outcomes: 1) does temperament predict outcomes in adulthood and 2) does childhood temperament predict outcomes above and beyond adult-based personality?

\section{Methods}




\section{Participants}

Participants consisted of 7,081 individuals from the National Longitudinal Survey of Youth 1979 - Child and Young Adult (NLSY79-CYA) sample. The National Longitudinal Survey of Youth 1979 (NLSY79) is an ongoing longitudinal study conducted by the U.S. Bureau of Labor Statistics (BLS). The NLSY79 began in 1979 and consisted of a (then) nationally representative sample of 12,686 men and women who were all 14 to 21 years of age ${ }^{22}$. As of 2018, the women of the NLSY79 were between the ages of 53 to 62 and there were 11,545 children born to the NLSY79 mothers. The NLSY79-CYA sample consists of the offspring of the original mothers of the NLSY79 sample.

Across all waves, ages ranged from infancy ( 0 years old) to 37 years $(M=15.24, S D=8.78)$. The average age in our sample at the final measurement occasion was 27.73 years old $(S D=4.87$, Min $=15, M a x=37)$. Among participants, $39.4 \%$ of the sample identified as white $(N=2,792), 36.2 \%$ as Black $(N=2,564), 23.4 \%$ as Hispanic/Latinx $(N=1,658)$, and $1.0 \%$ other $(N=67)$. There were 3,594 males $(50.8 \%)$ and 3,487 females $(49.2 \%)$. The last wave of data in our study was collected in 2016.

Participants were included in the present study if they had measures of childhood temperament and adult-based personality. Since this is a large panel study, participants who complete one measure are expected to have data for other measures (i.e., if participants had personality data, they also had outcome data). Thus, attrition analyses were conducted that compared individuals who only had temperament data versus those who were included in the present study (i.e., had temperament and adult-based personality data). Compared to individuals included in our study ( $N=$ $7,081)$, participants who only had temperament data $(n=2,039)$ scored lower on fearfulness $(t(1454)=3.60, p<.001, d$ $=-0.12)$, higher on insecure attachment $(t(2567.1)=-3.88, p<.001, d=0.11)$, and lower on sociability $(t(2289.7)=4.15$, $p<.001, d=-0.12)$. Additionally, participants who only had temperament data, compared to those in our study, included a larger proportion of White participants $\left(\chi^{2}(1)=409.95, p<.001\right)$, a smaller proportion of Black participants $\left(\chi^{2}(1)=\right.$ $260.10, p<.001)$, a smaller proportion of Hispanic participants $\left(\chi^{2}(1)=26.88, p<.001\right)$, and had lower education levels $(t(581.16)=5.64, p<.001, d=-0.97)$.

\section{Measures}

\section{Childhood Temperament}

Temperament was assessed in children ages 0 to $6(M=3.76, S D=2.01)$ using scales adapted from the Infant Behavior Questionnaire ${ }^{23}$, compliance scale ${ }^{24}$, and additional items selected by one of the creators of the compliance scale (Joseph Campos). From 1986-2000, all children ages 0-6 were assessed in the scales activity, compliance, fearfulness, insecure attachment, predictability, and positive affect; in 2002, children ages 2-6 were assessed; from the year 2004 and thereafter, only children ages 3-6 were assessed. All were maternal report. Sociability was assessed across the years with three items answered by the interviewer. Average Cronbach's alpha values were .69 or greater. The number of waves of data for any temperament dimension ranged from 1 to 4; 1,096 participants had 1 wave, 1,207 had 2 waves, 2,917 had 3 waves, and 1,861 had 4 waves. The temperament qualities had an average prediction interval of nearly 25 years with a max of over 30 years.

\section{Personality}

Personality was assessed using the Ten Item Personality Inventory $\left(\mathrm{TIPI}^{25}\right)$ in adolescents and adults $\left(M_{\mathrm{age}}=23.04\right.$, $S D_{\text {age }}=4.93$, Min $\left._{\text {age }}=15, M_{a x}=35\right)$ up until 2014. This measure assesses the Big Five personality traits ${ }^{26}$. The number of waves for personality ranged from 1-5; 729 participants had 1 wave, 1941 had 2 waves, 3,604 had 3 waves, and 807 had 4 waves.

\section{Outcomes}


Health. Included outcomes in the health domain include self-report health status and body mass index (BMI). Health status was assessed with a single-item measure asking, "How would you describe your present health?" and treated as an ordinal variable. Response options were on a Likert scale consisting of 1 (poor), 2 (fair), 3 (good), 4 (very good), and 5 (excellent). The last available wave of data for these variables were used as the outcome for each participant. BMI was calculated from the height and weight variables for each participant, standardized, and treated as continuous.

Internalizing. Included outcomes included diagnoses of anxiety and depression; record of ever seeing a counselor for emotional, behavioral, or mental problems; and record of ever attempting suicide. The variables were coded such that 1 indicated a response of "yes" during any available waves for a single participant and 0 indicated a response "no" at every wave (i.e., dummy-coded).

Externalizing. Included outcomes were a diagnosis of attention deficit hyperactivity disorder (ADHD), reported number of substances used across all available waves for a participant, and ever going to jail. For substance use, items asking if the participant had ever used one of eight substances (alcohol, cigarettes, cocaine, hallucinogens, marijuana, downers, inhalants, stimulants) were used to create a variable for the number of substances the individual has done. The variables for an ADHD diagnosis and ever going to jail were dummy-coded.

Cognition. Variables assessing cognitive performance consisted of a total score of a forwards and backwards digit span count, word recall, Peabody Individual Achievement Test (PIAT) math assessment, PIAT reading comprehension assessment, and PIAT reading recognition assessment ${ }^{27}$. Raw summary scores for each cognitive assessment were obtained directly from the NLSY Investigator database. Final cognition variables were standardized and treated as continuous.

Relationships and Family. Outcomes in the relationship domain included relationship satisfaction at the last available wave for a participant, record of ever being married, ever being divorced, number of marriages, and ever having children. The variables for ever being married, divorced, or having children were dummy-coded. There were three possible variables for relationship satisfaction, each asking about satisfaction with a different type of relationship (boyfriend/girlfriend, partner, spouse). Since participants did not have data for more than one variable at a given wave (as they could not have a girlfriend/boyfriend AND a spouse, for example), these three items were combined to form a single relationship satisfaction variable and was treated as ordinal.

Education, Career, and Financial. Included variables were highest degree obtained by the participant, being employed at the wave following their last personality assessment, median annual salary, and record of ever being the recipient of government financial assistance (i.e., welfare). Highest degree obtained was treated as an ordinal variable and its value was determined by the highest value across all available waves for a participant. Being employed and ever receiving welfare were dummy-coded. Median annual salary was calculated across all available waves for a participant, standardized, and treated as continuous.

Civic Engagement. Included variables were being religious and volunteering. The variables were dummy-coded. Control variables

Variables that have been previously used in past studies and that were of theoretical and practical relevance were included to account for potentially influential differences surrounding birth and early childhood of the participants. These variables were age at the last wave of the outcome variable, gender (male $=0$, female $=1$ ), race, mother's age at birth, whether or not the child was breastfed, number of weeks the mom was pregnant with the participant, child's height and weight at birth, whether the mother reported any drinking or smoking during pregnancy, and mother's highest education level. 


\section{Transparency and Openness}

Within this methods section, we report how we determined our final sample size through inclusion criteria, all measures used along with their psychometric properties, and we follow the APA Style Journal Article Reporting Standards $\left(\right.$ JARS $\left.^{28}\right)$. Data are freely accessible at https://www.nlsinfo.org/investigator and code for all data cleaning and analyses is available at https://osf.io/kyrq7/. The Institutional Review Board (IRB) at Washington University in St. Louis deemed this project exempt from IRB approval because it involves accessing a publicly available dataset and thus does not meet federal definitions under the jurisdiction of an IRB (ID\#: 202107190). The APA's ethical standards for conducting research were followed throughout the duration of this study. Data were analyzed using R, version 4.0.3 ${ }^{29}$ and the package brms ${ }^{30}$. This study's design and its analyses were not pre-registered.

\section{Analysis Plan}

Bayesian generalized linear regressions were conducted for each outcome with a) all temperament dimensions, b) all personality traits, and c) all temperament and personality entered simultaneously as predictors. All temperament and personality variables were standardized to aid in interpretation and model convergence. To calculate our primary parameter of interest - the incremental $\mathrm{R}^{2}$ values - all models were first fit without covariates. Then, only for the purpose of obtaining individual trait estimates that may be of interest (i.e., calculating the incremental $\mathrm{R}^{2}$ for the temperament models was no longer needed), models including covariates were fit. Priors were weakly regularizing and centered around 0 . Binomial distributions were used for any dichotomous outcome variables; cumulative distributions were used for ordinal variables; Poisson distributions were used for count variables; and student's t distributions were used for continuous variables. Parameter estimates (maximum a posterior probability (MAP) estimates) were extracted along with $95 \%$ credible intervals (Cls) and variance explained $\left(\mathrm{R}^{2}\right)$ values for each model. We used $95 \% \mathrm{Cls}$ to determine whether the $\mathrm{R}^{2}$ values were meaningful (i.e., the interval did not contain zero). Furthermore, for a traditional cut-off of $a=.05$, a power analysis indicated that we had $80 \%$ power to detect an odds ratio of 1.0693 per one standard deviation increase in a predictor variable ${ }^{31}$.

\section{Results}

\section{Childhood Temperament Predicting Adult Outcomes}

Generally, childhood temperament was a good predictor of future life outcomes, up to 30 years later (Fig. 1; also see Supplementary Figures S1-S7). For example, temperament was related to objective indicators such as BMI (5.76\%), educational attainment (4.44\%), and being incarcerated (2.25\%) over two decades later. Temperament was not associated with every outcome, however, even for outcomes that personality traits predicted (e.g., annual salary $(0.69 \%)$ ). Educational attainment $(4.44 \%$ vs $2.67 \%)$ and substance use $(0.87 \%$ vs $4.71 \%)$, as two examples, demonstrate the difference in predictive validity for childhood temperament and adulthood personality, respectively. Overall, despite being much closer in years between assessment and outcome, the explained variance from personality models was not that much greater than that of childhood temperament (see Supplementary Figures S1-S7 for $\mathrm{R}^{2}$ distributions for temperament- and personality-only models).

Since the primary goal of this paper was to view the sole and incremental explanatory power of the temperament relative to personality (i.e., the model $\mathrm{R}^{2}$ values), individual temperament estimates with the outcomes were of lesser interest. However, these estimates can be found in Supplementary Tables S1-S7 from models without covariates; Supplementary Tables S8a-14a from models with covariates; and Supplementary Table S15 for a comparison of estimates from models with and without covariates. 


\section{Independent Associations of Temperament and Personality for Life Outcomes}

Next, we sought to examine whether childhood temperament yielded incremental predictive validity of life outcomes over adult personality traits. For these models, all childhood temperament characteristics and all adult-based personality traits were entered as predictors simultaneously. To determine the incremental $\mathrm{R}^{2}$ value for childhood temperament within the combined model for any given outcome, the $\mathrm{R}^{2}$ from the adult-based personality-only model was subtracted from the total $\mathrm{R}^{2}$ for the combined model for that outcome (Table 1; Supplementary Figures S8-14). Individual estimates for each outcome from the personality-only models can be found in Supplementary Tables S1-S7 (without covariates); Supplementary Tables S8b-14b (with covariates); and Supplementary Table S16 for a comparison of estimates from models with and without covariates. 
Table 1

Incremental and Model $\mathrm{R}^{2}$ Values from Temperament-Only, Personality-Only, and Combined Models for All Outcomes

\begin{tabular}{|c|c|c|c|c|c|c|c|c|}
\hline \multirow{3}{*}{ Domain } & \multirow{3}{*}{ Outcome } & \multicolumn{7}{|c|}{ Model Type } \\
\hline & & \multicolumn{2}{|c|}{ Temperament } & \multicolumn{2}{|c|}{ Personality } & \multicolumn{2}{|c|}{ Combined } & \multirow{2}{*}{$\begin{array}{l}\text { Incremental } \\
R^{2}\end{array}$} \\
\hline & & $R^{2}$ & $\mathrm{Cl}$ & $R^{2}$ & $\mathrm{Cl}$ & $R^{2}$ & $\mathrm{Cl}$ & \\
\hline \multicolumn{9}{|l|}{ Health } \\
\hline & $\begin{array}{l}\text { Health Status } \\
\text { at Last Wave }\end{array}$ & 1.86 & {$[0.89,3.06]$} & 4.95 & {$[4.01,5.93]$} & 7.67 & {$[5.58,9.91]$} & $2.72^{P}$ \\
\hline & $\begin{array}{l}\text { BMl at Last } \\
\text { Wave }\end{array}$ & 5.76 & {$[4.14,7.53]$} & 5.44 & {$[4.57,6.31]$} & 5.92 & {$[4.30,7.76]$} & 0.48 \\
\hline \multicolumn{9}{|c|}{ Internalizing } \\
\hline & Anxiety & 4.16 & {$[1.29,8.09]$} & 5.42 & {$[3.17,8.02]$} & 9.43 & {$[4.85,14.57]$} & 4.01 \\
\hline & Depression & 4.85 & {$[1.63,9.13]$} & 5.30 & {$[3.00,7.94]$} & 15.16 & {$[8.97,21.21]$} & $9.86^{\top}$ \\
\hline & Counselor & 1.21 & {$[0.45,2.22]$} & 5.39 & {$[4.45,6.39]$} & 7.90 & {$[5.86,9.97]$} & $2.51^{P}$ \\
\hline & Suicide & 0.74 & {$[0.19,1.65]$} & 7.37 & {$[5.90,8.88]$} & 9.14 & {$[6.28,12.29]$} & $1.77^{\mathrm{P}}$ \\
\hline \multicolumn{9}{|c|}{ Externalizing } \\
\hline & $A D H D$ & 4.35 & {$[1.54,8.20]$} & 1.82 & {$[0.81,3.12]$} & 7.29 & {$[3.53,11.96]$} & $5.47^{\top}$ \\
\hline & Ever jail & 2.25 & {$[0.88,4.21]$} & 1.75 & {$[1.12,2.51]$} & 4.45 & {$[2.36,7.18]$} & 2.70 \\
\hline & $\begin{array}{l}\text { Number of } \\
\text { Substances }\end{array}$ & 0.87 & {$[0.27,1.70]$} & 4.71 & {$[3.78,5.71]$} & 6.82 & {$[4.76,9.06]$} & $2.11^{\mathrm{P}}$ \\
\hline \multicolumn{9}{|c|}{ Cognitive } \\
\hline & Digit Span & 5.54 & {$[3.66,7.58]$} & 2.13 & {$[1.50,2.85]$} & 7.56 & {$[5.39,9.90]$} & $5.42^{\top}$ \\
\hline & Word Recall & 9.01 & {$[3.45,15.67]$} & 2.37 & {$[1.02,4.07]$} & 11.24 & {$[5.01,18.38]$} & $8.88^{\top}$ \\
\hline & PIAT Math & 11.04 & {$[8.56,13.60]$} & 3.06 & {$[2.33,3.85]$} & 13.66 & {$[10.96,16.41]$} & $10.60^{\top}$ \\
\hline & $\begin{array}{l}\text { PIAT Read } \\
\text { Comprehension }\end{array}$ & 12.01 & {$[9.45,14.61]$} & 3.08 & {$[2.32,3.90]$} & 13.80 & {$[11.20,16.47]$} & $10.72^{\top}$ \\
\hline & $\begin{array}{l}\text { PIAT Read } \\
\text { Recognition }\end{array}$ & 10.36 & {$[7.95,12.85]$} & 2.74 & {$[2.04,3.50]$} & 11.99 & {$[9.63,14.52]$} & $9.25^{\top}$ \\
\hline \multicolumn{9}{|c|}{ Relationship \& Family } \\
\hline & Ever Married & 1.44 & {$[0.60,2.57]$} & 2.31 & {$[1.67,3.01]$} & 4.02 & {$[2.51,5.79]$} & 1.71 \\
\hline & Ever Divorced & 3.57 & {$[1.02,7.29]$} & 0.82 & {$[0.25,1.62]$} & 5.66 & {$[2.24,10.03]$} & $4.84^{\top}$ \\
\hline & Times Married & 1.57 & {$[0.62,2.93]$} & 2.26 & {$[1.48,3.10]$} & 4.28 & {$[2.40,6.76]$} & 2.03 \\
\hline & $\begin{array}{l}\text { Relationship } \\
\text { Satisfaction }\end{array}$ & 2.25 & {$[1.03,3.73]$} & 2.10 & {$[1.43,2.84]$} & 4.57 & {$[2.84,6.57]$} & 2.47 \\
\hline & $\begin{array}{l}\text { Ever Have } \\
\text { Children }\end{array}$ & 4.01 & {$[2.46,5.76]$} & 2.47 & {$[1.82,3.14]$} & 5.42 & {$[3.64,7.32]$} & $2.95^{\top}$ \\
\hline
\end{tabular}


Education, Career,

Financial

\begin{tabular}{|c|c|c|c|c|c|c|c|}
\hline Highest Degree & 4.44 & {$[2.87,6.29]$} & 2.67 & {$[2.00,3.39]$} & 7.87 & {$[5.82,10.06]$} & $5.20^{\top}$ \\
\hline $\begin{array}{l}\text { Employed at } \\
\text { Last Wave }\end{array}$ & 1.30 & {$[0.50,2.32]$} & 1.34 & {$[0.85,1.90]$} & 2.39 & {$[1.21,3.82]$} & 1.04 \\
\hline Annual Salary & 0.69 & {$[0.34,1.12]$} & 1.37 & {$[1.02,1.77]$} & 1.29 & {$[0.80,1.90]$} & -0.09 \\
\hline $\begin{array}{l}\text { Ever Receive } \\
\text { Welfare }\end{array}$ & 3.46 & {$[1.59,5.84]$} & 2.43 & {$[1.66,3.36]$} & 6.60 & {$[3.72,10.22]$} & $4.16^{\top}$ \\
\hline \multicolumn{8}{|l|}{ Civic Engagement } \\
\hline Religious & 0.74 & {$[0.16,1.82]$} & 0.24 & {$[0.06,0.55]$} & 2.33 & {$[0.78,4.95]$} & $2.08^{\top}$ \\
\hline $\begin{array}{l}\text { Ever } \\
\text { Volunteered }\end{array}$ & 2.58 & {$[1.30,4.15]$} & 2.12 & {$[1.48,2.81]$} & 4.53 & {$[2.85,6.54]$} & $2.41^{\top}$ \\
\hline \multicolumn{8}{|c|}{$\begin{array}{l}\text { Note. } \mathrm{R}^{2} \text { values are presented as percentages. Results are from models without covariates. The incremental model } \\
\mathrm{R}^{2} \text { is the percentage of the combined model } \mathrm{R}^{2} \text { not accounted for by adult-based personality (i.e., has personality } \\
\text { model } \mathrm{R}^{2} \text { subtracted out). Bold values indicate the larger } \mathrm{R}^{2} \text { value between the temperament-only and personality- } \\
\text { only models for each outcome. In the "Incremental" column, if the combined and personality-only } \mathrm{R}^{2} \text { credible } \\
\text { intervals did not overlap, then temperament was a meaningful predictor above and beyond personality in terms of } \\
\text { incremental predictive validity (these values are marked by a } \mathrm{T} \text { superscript). Alternatively, if the combined and } \\
\text { temperament-only } \mathrm{R}^{2} \text { credible intervals did not overlap, then personality was a meaningful predictor above and } \\
\text { beyond temperament (these values are marked by a } P \text { superscript). To ease in readability, values in the } \\
\text { "Incremental" column indicate outcomes for which temperament explained incremental variance are also bolded. }\end{array}$} \\
\hline
\end{tabular}

In general, temperament provided a number of incremental predictions above personality, despite personality being assessed closer in time, as temperament was, on average, assessed over 20 years prior to these outcomes (Table 1). Cognitive outcomes, a diagnosis of depression or ADHD, and highest degree obtained were amongst the most prominent outcomes in which temperament provided incremental variance above adult-based personality. Incremental variances explained for temperament ranged from just above $2 \%$ to above $10 \%$ - levels of association that are high for psychology, especially when considering the nearly thirty-year timespan. For individual estimates for each outcome from the combined models, see Supplementary Tables S1-S7 (without covariates) and Supplementary Tables S8cS14c (with covariates).

\section{Discussion}

Within this paper, we tested the predictive validity of childhood temperament for life outcomes up to thirty years later. Two main findings emerged. First, temperament measured between ages $0-6$ was able to predict a wide-ranging number of life outcomes. Second, temperament often provided incremental predictive validity above adult-based personality, suggesting that there is unique information in childhood assessments despite being assessed farther away in time. These findings establish the importance of both distal and proximal personality predictors of outcomes, supporting the need to understand who an individual is throughout the lifespan.

\section{Predictive Validity of Temperament}

For a set of traits that were measured between infancy and age six, the ability of temperament to predict outcomes in adulthood, decades later, was noteworthy. Consistent with past research ${ }^{32,33}$, our temperament assessments 
completed at an average age of 3.76 years lend support that personality can be measured early on in life and have predictive validity for important life outcomes decades later.

Our wide-ranging array of outcome variables further supports the broad and far-reaching predictive abilities of childhood temperament. Many past studies with temperament and adult-based personality often limited their investigations of prediction with temperament to psychopathology-related outcomes ${ }^{34}$ while those that examined other outcomes typically remained in a single outcome domain (e.g., occupations ${ }^{35}$ ). Thus, our study indeed found that early assessments of temperament are associated with a broad array of outcomes, up to decades later. Notable examples include BMI, cognitive ability, divorce, educational attainment, and civic engagement.

While not reported in the results but available in the supplementary materials, across all domains, the temperament trait of compliance emerged as the most frequent individual predictor, followed closely by sociability and predictability. Compliance is believed to represent a childhood precursor of agreeableness, but agreeableness-related traits are typically not included as a major dimension in popular temperament models but are included in childhood personality models inspired by the Big Five ${ }^{32}$. Part of this could be due to variation in methodology of assessing these temperament traits, as this agreeableness-related factor is the broadest and largest dimension that has emerged from parental descriptions of child temperament ${ }^{36}$ but emerges less frequently through other assessment methods (e.g., self-report, laboratory tasks). Since this trait was in fact reported on by parents in our study, its prominence in predicting outcomes could reflect the parents' concern with managing the child's behavior and avoiding parent-child conflict, thus perhaps over-reporting on or emphasizing this quality in their child. Agreeableness as a personality trait is related to outcomes in various domains, including interpersonal, social, and health outcomes ${ }^{11,37-39}$ so it is not entirely surprising this possible childhood precursor of agreeableness is related to a vast number of outcomes as well. Furthermore, one empirically derived personality taxonomy for children, the Hierarchical Personality Inventory for Children $\left(\mathrm{HiPIC}^{40}\right)$, found that compliance represented a blend of benevolence and, more interestingly, conscientiousness. Given conscientiousness's many associations with beneficial outcomes ${ }^{38,41-43}$, our findings of compliance being associated with the greatest number of outcomes is perhaps even more to be expected.

There are also reasons as to why the other two most frequent temperament predictors, predictability and sociability, emerged as often as they did. First, predictability, also sometimes called regularity, refers to the "predictability" of a child's biological and behavioral patterns ${ }^{44,45}$. With age, the children's daily schedules and personal habits also appear to be consistent with their earlier predictability levels. Highly regular children like setting schedules for accomplishing tasks and enjoy structure in their lives, whereas highly irregular children have more difficulty adapting to set routines and forming regular habits and mood patterns, which can precede behavioral problems later in life ${ }^{46-48}$. However, children exhibiting these irregular tendencies also can adjust better to unexpected changes in their routine and are more flexible in lifestyle changes. Predictability's associations with setting schedules and routines as well as consistent mood patterns is reflective of both conscientiousness and neuroticism; two traits that are associated with numerous outcomes in many domains 38,49 .

Additionally, past research has suggested sociability be considered a lower-order quality of the broader dimension positive emotionality as opposed to constituting its own independent trait ${ }^{36}$. Positive emotionality and the qualities it is believed to subsume (e.g., sociability, shyness, dominance) are related to future scores on extraversion ${ }^{5,50}$. Extraversion is linked to positive outcomes in adulthood, particularly those related to social and well-being outcomes ${ }^{51-}$ ${ }^{54}$. Greater well-being itself is positively related to beneficial outcomes in several life domains ${ }^{38}$, serving as one path by which childhood sociability is linked to outcomes in different domains.

\section{Reasons for Incremental Predictive Validity of Temperament over Personality}


We found evidence for a lifespan perspective, such that it mattered "where you start and finish." It is beneficial to measure individual differences more than a single time over the life course, with childhood being an important time period for understanding adult outcomes. Not only did temperament provide incremental validity, but it evidenced stronger initial predictions across a number of outcomes, despite the fact that the lag in time between assessment and outcome was decades longer for temperament than personality.

A few reasons may explain why childhood is important to understand adult outcomes. First, these results suggest there are childhood-specific processes, as outlined by Hill et al. (2019), that relate childhood individual differences to adult outcomes that are separate from adult processes (i.e., differential pathways). For example, personality measures better predicted substance use compared to temperament assessments. One potential reason why is that the processes that relate individual differences to those outcomes are more relevant for adults than children. Behaviors that influence substance use are better assessed with adult personality measures because they either have content that better assesses those process or because the processes are assessed closer in time to outcomes. This reasoning could similarly be why temperament better predicted an ADHD diagnosis, as diagnoses are often made around age six ${ }^{55}$.

Alternatively, the opportunities and snares hypothesis could offer another explanation. As Hill et al. (2019) point out, childhood personality measures are important because of the sensitive period of childhood due to its time-limited nature. The development that occurs early in life can be consequential to future outcomes, especially if this development primarily occurs in a limited span of time and/or the paths one is then led down cannot be reversed. If temperament traits are an acceptable proxy of an infant or child's functioning and healthy development, when cognitive abilities are also being largely formed and solidified (especially apparent when considering the long-term stability of $\left.\mathrm{IQ}^{56}\right)$, then future personality traits would offer little, if any, predictive validity not already captured by temperament. This could explain why temperament assessments did a good job at predicting educational outcomes over and above personality because education is an important childhood experience that is cumulative in nature.

\section{Limitations and Conclusion}

While our study was a powerful test of the incremental predictive validity of temperament compared to the Big Five personality traits using a representative sample assessed over three decades, there were a few limitations. First, we were limited by our measures in the temperament qualities that we could examine. Second, different reporting methods were used (parent, self) which have been differently associated with life outcomes ${ }^{41}$. Third, an alternative explanation for the findings is content and/or structural differences between the two sets of individual differences ${ }^{2,57}$. It is hard to address whether these factors are driving the differences as it is difficult to take an adult taxonomy and apply it to children. Behavioral expression of personality differs across age which is one of the reasons why the Little Six ${ }^{2}$ rather than the Big Five, for example, is found in childhood.

Using a large-scale longitudinal study across a 30-year time frame, we identified non-redundant predictions of life outcomes for temperament and personality. Temperament explained the most variance for outcomes such as cognitive ability and educational attainment whereas personality performed best for outcomes such as health status, substance use, and most internalizing outcomes. Our results highlight the benefit of a lifespan approach to understanding life outcomes, where adult-based outcomes are informed by child-based assessments.

\section{Declarations}

\section{Data Availability Statement}


Data are drawn from the publicly available National Longitudinal Survey of Youth 1979 - Child and Young Adult sample ${ }^{22}$ which is freely accessible at https://www.nlsinfo.org/investigator. The raw data used for the current study are available at the study's OSF page (https://osf.io/kyrq7/).

\section{Author Contributions}

AJW and JJJ wrote the main manuscript text. AJW performed all statistical analyses and created all figures and tables. Both authors reviewed and edited the manuscript.

\section{Additional Information}

The author(s) declare no competing interests.

\section{References}

1. Goldsmith, H. H. et al. Roundtable: What is temperament? Four approaches. Child Development 58, 505592 (1987).

2. Soto, C. J., \& John, O. P. Traits in transition: the structure of parent-reported personality traits from early childhood to early adulthood. Journal of Personality 82, 182-199 (2014).

3. Soto, C. J., \& Tackett, J. L. Personality traits in childhood and adolescence: Structure, development, and outcomes. Current Directions in Psychological Science 24, 358-362 (2015).

4. Zentner, M., \& Bates, J. E. Child temperament: An integrative review of concepts, research programs, and measures. International Journal of Developmental Science 2, 7-37 (2008).

5. Caspi, A., \& Shiner, R. L. Personality Development. in Handbook of child psychology: Social, emotional, and personality development (eds. Eisenberg, N., Damon, W., \& Lerner, R. M.) 300-365 (John Wiley \& Sons, Inc., 2006).

6. Tang, A. et al. Infant behavioral inhibition predicts personality and social outcomes three decades later. PNAS 117, 9800-9807 (2020).

7. Caspi, A., \& Shiner, R. Temperament and personality. in Rutter's child and adolescent psychiatry (eds. Rutter, M., Bishop, D., Pine, D., Scott, S., Stevenson, J., Taylor, E., \& Thapar, A.) 182-198 (Wiley Blackwell, 2008).

8. Asendorpf, J. B., Denissen, J. J., \& Van Aken, M. A. (2008). Inhibited and aggressive preschool children at 23 years of age: personality and social transitions into adulthood. Developmental psychology 44, 997-1011 (2008).

9. Roberts, B. W., \& DelVecchio, W. F. The rank-order consistency of personality traits from childhood to old age: a quantitative review of longitudinal studies. Psychological bulletin 126, 3-25 (2000).

10. Hampson, S. E., \& Goldberg, L. R. (2006). A first large cohort study of personality trait stability over the 40 years between elementary school and midlife. Journal of Personality and Social Psychology 91, 763-779 (2006).

11. Beck, E. D., \& Jackson, J. J. A mega-analysis of personality prediction: Robustness and boundary conditions. Journal of Personality and Social Psychology, (2021).

12. Fraley, R. C., \& Roberts, B. W. Patterns of continuity: a dynamic model for conceptualizing the stability of individual differences in psychological constructs across the life course. Psychological review 112, 60-74 (2005).

13. Hill, P. L., Edmonds, G. W., \& Jackson, J. J. Pathways linking childhood personality to later life outcomes. Child Development Perspectives 13, 116-120 (2019).

14. Kappe, R., \& Van Der Flier, H. Predicting academic success in higher education: what's more important than being smart?. European Journal of Psychology of Education 27, 605-619 (2012). 
15. Véronneau, M. H., Hiatt Racer, K., Fosco, G. M., \& Dishion, T. J. The contribution of adolescent effortful control to early adult educational attainment. Journal of Educational Psychology 106, 730-743 (2014).

16. Spengler, M., Brunner, M., Damian, R. I., Lüdtke, O., Martin, R., \& Roberts, B. W. Student characteristics and behaviors at age 12 predict occupational success 40 years later over and above childhood IQ and parental socioeconomic status. Developmental psychology 51, 1329-1340 (2015).

17. Hampson, S. E., Goldberg, L. R., Vogt, T. M., \& Dubanoski, J. P. Forty years on: teachers' assessments of children's personality traits predict self-reported health behaviors and outcomes at midlife. Health psychology 25, 57-64 (2006).

18. Friedman, H. S., Tucker, J. S., Schwartz, J. E., Tomlinson-Keasey, C., Martin, L. R., Wingard, D. L., \& Criqui, M. H. Psychosocial and behavioral predictors of longevity: The aging and death of the" Termites.". American Psychologist 50, 69-78 (1995).

19. D'Amico, E. J., Ellickson, P. L., Collins, R. L., Martino, S., \& Klein, D. J. Processes linking adolescent problems to substance-use problems in late young adulthood. Journal of studies on alcohol 66, 766-775 (2005).

20. Mount, M., Ilies, R., \& Johnson, E. Relationship of personality traits and counterproductive work behaviors: The mediating effects of job satisfaction. Personnel psychology 59, 591-622 (2006).

21. Salgado, J. F. The Big Five personality dimensions and counterproductive behaviors. International journal of selection and assessment 10, 117-125 (2002).

22. Bureau of Labor Statistics, U.S. Department of Labor, and National Institute for Child Health and Human Development. Children of the NLSY79, 1979-2016. Produced and distributed by the Center for Human Resource Research (CHRR), (The Ohio State University. Columbus, OH, 2021).

23. Rothbart, M. K. Measurement of temperament in infancy. Child Development 52, 569-578 (1981).

24. Baker, P. C. \& Mott, F. L. NLSY child handbook, 1989: A guide and resource document for the National Longitudinal Survey of Youth, 1986 Child Data. (Columbus, OH: Center for Human Resource Research, 1989).

25. Gosling, S. D., Rentfrow, P. J., \& Swann, W. B. A very brief measure of the Big-Five personality domains. Journal of Research in Personality 37, 504-528 (2003).

26. Goldberg, L. R. An alternative "description of personality": The Big-Five factor structure. Journal of Personality and Social Psychology 59, 1216-1229 (1990).

27. Markwardt, F. C. Peabody individual achievement test-revised. (Circle Pines, MN, American Guidance Service, 1989).

28. Kazak, A. E. Editorial: Journal article reporting standards. American Psychologist 73, 1-2 (2018).

29. R Core Team. R: A language and environment for statistical computing. R Foundation for Statistical Computing. (Vienna, Austria, 2021).

30. Bürkner, P. brms: An R Package for Bayesian Multilevel Models Using Stan. Journal of Statistical Software 80, 128 (2017).

31. Hsieh, F. Y., Bloch, D. A., \& Larsen, M. D. A simple method of sample size calculation for linear and logistic regression. Statistics in medicine 17, 1623-1634 (1998).

32. Rothbart, M. K., \& Bates, J. E. Temperament. in Handbook of child psychology: Social, emotional, and personality development. (eds. Eisenberg, N., Damon, W. \& Lerner, R. M.) 99-166 (John Wiley \& Sons, Inc., 2006).

33. Shiner, R., \& Caspi, A. Personality differences in childhood and adolescence: Measurement, development, and consequences. Journal of Child Psychology and Psychiatry 44, 2-32 (2003).

34. De Pauw, S. S., \& Mervielde, I. Temperament, personality and developmental psychopathology: A review based on the conceptual dimensions underlying childhood traits. Child Psychiatry \& Human Development 41, 313-329 
(2010).

35. Blatný, M., Millová, K., Jelínek, M., \& Osecká, T. Personality predictors of successful development: Toddler temperament and adolescent personality traits predict well-being and career stability in middle adulthood. PLoS ONE 10, (2015).

36. Mervielde, I., De Clercq, B., De Fruyt, F., \& Van Leeuwen, K. Temperament, personality, and developmental psychopathology as childhood antecedents of personality disorders. Journal of personality disorders 19, 171-201 (2005).

37. Robins, R. W., Caspi, A., \& Moffitt, T. E. It's not just who you're with, it's who you are: Personality and relationship experiences across multiple relationships. Journal of personality 70, 925-964 (2002).

38. Ozer, D. J., \& Benet-Martinez, V. Personality and the prediction of consequential outcomes. Annu. Rev. Psychol. 57, 401-421 (2006).

39. Jensen-Campbell, L. A. et al. Agreeableness, extraversion, and peer relations in early adolescence: Winning friends and deflecting aggression. Journal of Research in Personality 36, 224-251 (2002).

40. Mervielde, I., \& De Fruyt, F. Assessing children's traits with the Hierarchical Personality Inventory for Children. in Big Five assessment. (eds. de Raad, B. \& Perugini, M.) 129-142 (Ashland, OH, Hogrefe \& Huber Publishers, 2002).

41. Jackson, J. J., Connolly, J. J., Garrison, S. M., Leveille, M. M., \& Connolly, S. L. Your friends know how long you will live: A 75-year study of peer-rated personality traits. Psychological Science 26, 335-340 (2015).

42. Bogg, T., \& Roberts, B. W. Conscientiousness and health-related behaviors: a meta-analysis of the leading behavioral contributors to mortality. Psychological bulletin 130, 887-919 (2004).

43. Hill, P. L., \& Jackson, J. J. The invest-and-accrue model of conscientiousness. Review of General Psychology 20, 141-154 (2016).

44. Olafsen, K. S., Ulvund, S. E., Torgersen, A. M., Wentzel-Larsen, T., Smith, L., \& Moe, V. Temperamental adaptability, persistence, and regularity: parental ratings of Norwegian infants aged 6 to 12 months, with some implications for preventive practice. Infant mental health journal 39, 183-197 (2018).

45. Thomas, A., \& Chess, S. Temperament and development. (Brunner/Mazel, 1977).

46. Lahey, B. B., Van Hulle, C. A., Keenan, K., Rathouz, P. J., D’Onofrio, B. M., Rodgers, J. L., \& Waldman, I. D. Temperament and parenting during the first year of life predict future child conduct problems. Journal of abnormal child psychology 36, 1139-1158 (2008).

47. Burleson, J. A., \& Kaminer, Y. Does temperament moderate treatment response in adolescent substance use disorders?. Substance Abuse 29, 89-95 (2008).

48. Slobodskaya, H. R., Safronova, M. V., \& Windle, M. Personality, temperament and adolescent adjustment in modern Russia. Personality and Individual Differences 39, 167-178 (2005).

49. Donnellan, M. B., Oswald, F. L., Baird, B. M., \& Lucas, R. E. The Mini-IPIP scales: Tiny-yet-effective measures of the Big Five factors of personality. Psychological Assessment 18, 192-203 (2006).

50. Caspi, A. et al. Children's behavioral styles at age 3 are linked to their adult personality traits at age 26. Journal of personality 71, 495-514 (2003).

51. DeNeve, K. M., \& Cooper, H. The happy personality: a meta-analysis of 137 personality traits and subjective wellbeing. Psychological bulletin 124, 197-229 (1998).

52. Soto, C. J. Is happiness good for your personality? Concurrent and prospective relations of the big five with subjective well-being. Journal of personality 83, 45-55 (2015).

53. Specht, J., Egloff, B., \& Schmukle, S. C. Examining mechanisms of personality maturation: The impact of life satisfaction on the development of the Big Five personality traits. Social Psychological and Personality Science 4, 
181-189 (2013).

54. Paunonen, S. V. Big Five factors of personality and replicated predictions of behavior. Journal of personality and social psychology 84, 411-424 (2003).

55. Visser, S. N. et al. Trends in the parent-report of health care provider-diagnosed and medicated attentiondeficit/hyperactivity disorder: United States, 2003-2011. Journal of the American Academy of Child \& Adolescent Psychiatry 53, 34-46 (2014).

56. Deary, I. J. The stability of intelligence from childhood to old age. Current Directions in Psychological Science 23, 239-245 (2014).

57. Tackett, J. L. et al. The hierarchical structure of childhood personality in five countries: Continuity from early childhood to early adolescence. Journal of Personality 80, 847-879 (2012).

\section{Figures}

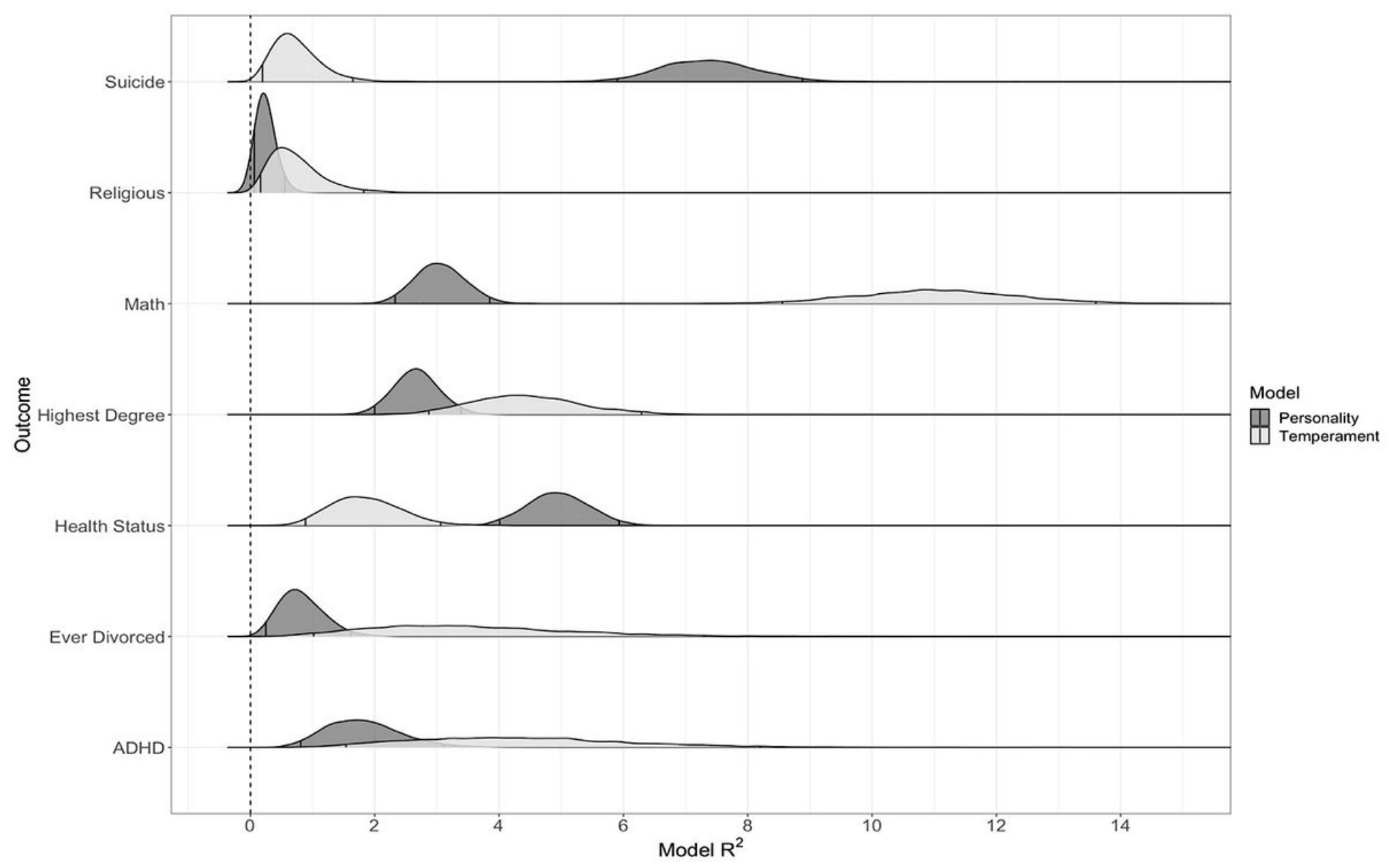

Figure 1

$R^{2}$ distributions for temperament- and personality-only models are presented above for select outcomes. $R^{2}$ values are presented as percentages. The $\mathrm{R}^{2}$ for the temperament-only models is plotted in light gray. The $\mathrm{R}^{2}$ for the adult-based personality-only models is plotted in dark gray. The $95 \%$ credible intervals, representing the $\mathrm{R}^{2}$ values that were present in $95 \%$ of the posterior distributions, are outlined in each distribution.

\section{Supplementary Files}


This is a list of supplementary files associated with this preprint. Click to download.

- NSRSupplementaryFigures.docx

- NSRSupplementaryTables.docx 